\title{
Performance Study of Maximum Power Point Tracking (MPPT) Based on Type-2 Fuzzy Logic Controller on Active Dual Axis Solar Tracker
}

\author{
Imam Abadi ${ }^{1, *}$, Qurrotul Uyuniyah ${ }^{1}$, Dwi Nur Fitriyanah ${ }^{1}$, Yahya Jani $^{2}$, and \\ Kamaruddin Abdullah ${ }^{3}$
}

\author{
${ }^{1}$ Department of Engineering Physics, Institut Teknologi Sepuluh Nopember, Jl. Teknik Kimia, \\ Surabaya 60111, East Java, Indonesia \\ ${ }^{2}$ Department of Biology and Environmental Science, Linnaeus University, Stuvaregatan 4 \\ SE-392 31 Kalmar, Sweden \\ ${ }^{3}$ Graduate School of Renewable Energy, Darma Persada University, Jl. Taman Malaka \\ Selatan No. 22, Pondok Kelapa, East Jakarta 13450, Indonesia
}

\begin{abstract}
World energy consumption increases with time, so that occur an energy imbalance. Many breakthroughs have developed to utilize renewable energy. The photovoltaic system is one of the easy-to-use renewable energies. The power conversion from PV fixed is still low, so the PV system is designed using the active dual-axis solar tracker. The PV tracker position can be adjusted to change the sun position to get maximum efficiency. The active dual-axis solar tracker system is integrated with the maximum power point tracking (MPPT) algorithm to keep PV operating at a maximum power point even though input variations change. The active dual-axis solar tracker system integrated with the maximum power point tracking (MPPT) algorithm to keep PV operating at a maximum power point even though input variations change. Tracking test simulation had done by comparing the output power of a fixed PV system with the active dual-axis solar tracker. Type-2 fuzzy logic based MPPT successfully increased the average output power by $10.48 \%$ with the highest increase of 17.48\% obtained at 15:00 West Indonesia Time (GMT+7). The difference in power from a fixed PV system with the active dual-axis solar tracker of $36.08 \mathrm{~W}$ is from the output power worth 206.3 to $242.4 \mathrm{~W}$.
\end{abstract}

Keywords: Clean energy, fuzzy logic, maximum power point, renewable energy, solar tracker.

\section{Introduction}

Review statistics that record the consumption of energy in the world showed there are increased significantly since the year 2006 until 2016. Consumption of energy in Indonesia

\footnotetext{
* Corresponding author: imamabadi02@gmail.com
} 
recorded until the year 2016, oil and coal into a source of energy major 's most lots used $[1]$.

The environmental problem caused by fuel such as warming global, pollution and the depletion of the source of energy from fossil led researchers started to develop some breakthroughs to harness energy renewable [2]. The use of renewable energy in Indonesia is still very limited. Energy new renewable successfully produced $2.6 \times 10^{6} \mathrm{t}[1]$ due to the limited conversion technologies energy and high production costs.

System photovoltaic is one of the energies of renewable that is free of pollution and maintenance as well as easy to use with the purpose of a stand-alone [2-4]. Indonesia has the potential renewable energy more than $441 \mathrm{GW}$ newly realize $8.89 \mathrm{GW}$. Indonesia's geographical location, which is crossed by the equator, makes Indonesia has the potential to develop a solar power plant. Semiconductors material in solar cells absorb rays of the sun and broke the electron from the atom, which then becomes energy electricity [3], but the conversion efficiency of PV normal still low [5]. The movement of the sun was not sure to influence intensity light and irradiate man who can be accepted by cell solar $[5,6]$. Module PV can collect a lot of energy and an increase in efficiency when combined with the solar tracker system. The use of total solar tracker dual axes on PV able to enhance the efficiency of energy amounted to $40 \% \mathrm{yr}^{-1}[6]$.

A solar tracker is a tool that orients panel solar is continuous following the change of the position of the sun and makes sure that the position of the panel solar upright straight towards the sun so that the maximum efficiency [5]. A solar tracker categorizes into a system of active and passive. The system passively using materials that have the principle of thermal expansion that is cheap and simple to compare with the active system. However, it only depends on temperature changes and has a low accuracy value, so this method is not appropriate to use in the solar tracker [3, 7]. Enhancing an accuracy can be obtained by using the active system by moving the PV based on the movement of the sun through the actuator motors DC [7]. Based on the movement of degrees of freedom, there is a one- axis (single-axis) [8] and two-axis (dual-axis) solar tracker [9]. Type dual-axis solar tracker use so that the panel solar can move on towards the west to east and north to south as well as add to the burden of power that generated [10].

Panel Solar has some drawbacks such as the cost of installation are high, the efficiency of conversion of energy that is low and nonlinearity between voltage and current output from panel solar $[2,6,11]$. The MPPT takes to ensure panel solar still operates at the Maximum Power Point (MPP) in the variation of conditions of irradiation and temperature. The MPPT method includes Artificial Neural Network, Genetic Algorithm, and fuzzy logic [12].

The MPPT method-based logic fuzzy type-2 that used is considered suitable applied in the plant with high uncertainty. Fuzzy logic type- 2 is the development of type- 1 fuzzy logic introduced by Zadeh [13]. The solution to overcome the problems is with the development method of control of intelligence, i.e., logic fuzzy type 2 in MPPT, which is combined with a solar tracker two axes-based photo resistive tracking method.

\section{Research methodology}

\subsection{Modeling active dual axis solar tracker and PV}

The module specifications used in designing PV modeling given in Table 1. 
Table 1. PV module specifications

\begin{tabular}{ll}
\hline \multicolumn{1}{c}{ Parameter } & \multicolumn{1}{c}{ Value } \\
\hline Maximum Power (Pmax) & $250 \mathrm{~W}$ \\
Maximum Current (IMPP) & $8.34 \mathrm{~A}$ \\
Maximum Voltage (VMPP) & $30 \mathrm{~V}$ \\
Open Circuit Voltage (VOC) & $36.8 \mathrm{~V}$ \\
Short Circuit Current (ISC) & $9 \mathrm{~A}$ \\
\hline
\end{tabular}

The PV module specifications listed in Table 1 obtained from the PV datasheet. Wind speed is an additional input that enters to PV, besides the temperature and solar irradiation that influences temperature input. The values of constants are w1, w2, and w3 listed in Table 2. Also, modeling output PV when STC conditions $\left(1000 \mathrm{~W} \mathrm{~m}^{-2}\right.$ and $\left.25^{\circ} \mathrm{C}\right)$ yield curve is as Figure 1.

$$
T_{\text {module }}=w 1 * T_{\text {ambient }}+w 2 * \text { Irradiance }+w 3 * \text { Wind Speed }+ \text { constant }
$$

Table 2. Input parameter coefficients

\begin{tabular}{cccc}
\hline Modul & w1 & w2 & w3 \\
\hline Average Polycrystalline & 0.954 & 0.03 & -1.629 \\
\hline
\end{tabular}
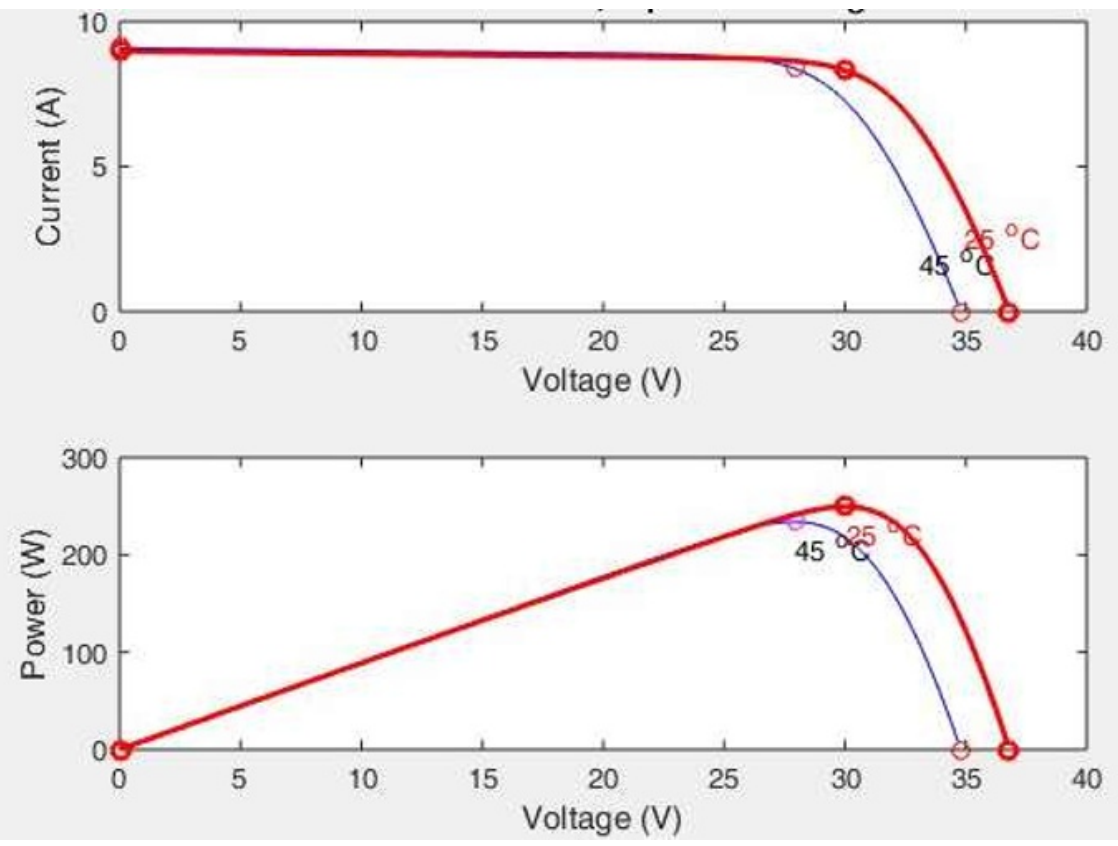

Fig. 1. PV Module characteristic curve

Figure 1 shows that the power generated by the PV module when the STC condition shows a value of $250 \mathrm{~W}$ and the voltage and current have values of almost $30 \mathrm{~V}$ and $8.34 \mathrm{~A}$ so that the modeling carried out is close to the value in the PV datasheet. Modeling active dualaxis solar tracker consists of several components, namely LDR sensor modeling, DC 
motors, and PV modeling. DC motor modeling derived from Kirchoff II's Law and Newton's II Law. LDR sensor modeling uses a voltage divider circuit to convert the sensor output in the form of resistance to voltage so that it can process inside the controller. The input of the LDR sensor modeling is the angle and intensity of sunlight that obtained from data collection for one day starting at $(6: 00)$ to $(17: 00)$ West Indonesia Time (GMT+7). Sensor LDR used there are four, namely sensor LDR West, sensor LDR East, sensor LDR North, and sensor LDR South. Input angle for West LDR sensor is yaw angle, East LDR sensor is azimuth angle, while North LDR sensor is altitude angle and South LDR sensor is pitch angle. The relationship between LDR sensor input and output is as follows,

$$
\log R=-3 / 4 \log I+5
$$

The intensity value of the light effect on the PV system is obtained using Equation (3).

$$
\mathrm{I}_{\mathrm{eff}}=\mathrm{I}_{\max } \sin \theta
$$

\subsection{Modeling DC-DC converter}

Converters DC-DC used is the buck-boost. Converter DC-DC buck-boost is a converter type DC-DC capable of producing an output voltage that is higher or lower than the input voltage into the converter. The parameters of the buck-boost components can found by the Equation below.

$$
\begin{gathered}
V_{\text {out }}=\frac{-D}{1-D} V_{\text {in }} \\
R=\frac{V_{\text {out }}}{I_{\text {out }}} \\
L_{\text {min }}=\frac{(1-D)^{2}}{2 f} R \\
C=\frac{V_{\text {out }} \cdot D}{R \cdot \Delta V_{\text {out }} \cdot f}
\end{gathered}
$$


Table 3. Input parameter coefficients

\begin{tabular}{|c|c|}
\hline Parameter & Value \\
\hline Input Voltage (Vin) & $28.9 \mathrm{~V}$ \\
\hline Output Voltage (Vout) & $30 \mathrm{~V}$ \\
\hline Output Current (Iout) & $8.34 \mathrm{~A}$ \\
\hline Switching Frequency & $30 \mathrm{kHz}$ \\
\hline Inductor & $14 \mu \mathrm{H}$ \\
\hline Capacitor & $5 \mathrm{mF}$ \\
\hline Resistive Load & $4 \mathrm{Ohm}$ \\
\hline
\end{tabular}

The specifications of the buck-boost converter used in the system based on calculations in Equations (4) to Equation (7) can see in Table 3.

\subsection{Primary data collection}

Primary data collection was carried out during $11 \mathrm{~h}$ of operation, starting from 06:00 to 17:00 West Indonesia Time on the 25th of April, 2018. Data collection routes starting from the 10th of November Institute of Technology to Jembatan Merah Plaza and then returning to Institut Teknologi Sepuluh Nopember. Primary data taken in the form of environmental data are PV module temperature, solar irradiation, and wind speed. Figure 4 is one of the documentation of the process of taking wind speed data taken using an anemometer measurement tool. The tools used in the data collection process include an infrared thermometer, a pyranometer, and an anemometer.

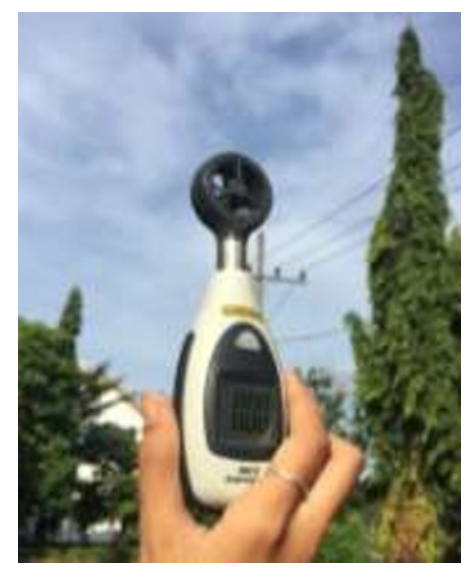

Fig. 2. Retrieval of wind speed data

\subsection{Fuzzy logic and fuzzy type-2 controller design}

The fuzzy logic control system consists of four elements, namely fuzzification, inference system, rule base, and defuzzification. Inputs for fuzzy logic control are an error (e) and delta error (e) with the output duty cycle (D). 


$$
\begin{array}{r}
e(k)=\frac{d P}{d V}(k)-\frac{d P}{d V}(K-1) \\
\Delta e(k)=e(k)-e(k-1)
\end{array}
$$

Membership function (MF) used in fuzzy logic input and output is 5 with a combination of trapezoidal and triangular shapes. The MF used includes NB (Negative Big), NS (Negative Small), ZE (Zero), PS (Positive Small), and PB (Positive Big). Membership function of input error (e) and delta errors (e) show by Figure 3 with 3 MF triangles and $2 \mathrm{MF}$ trapezoidal in shape at the edges.

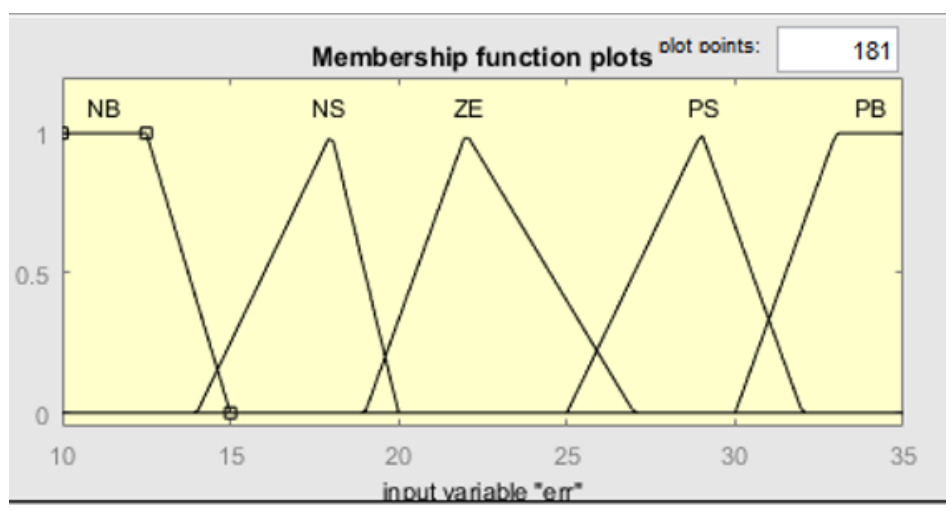

(a)

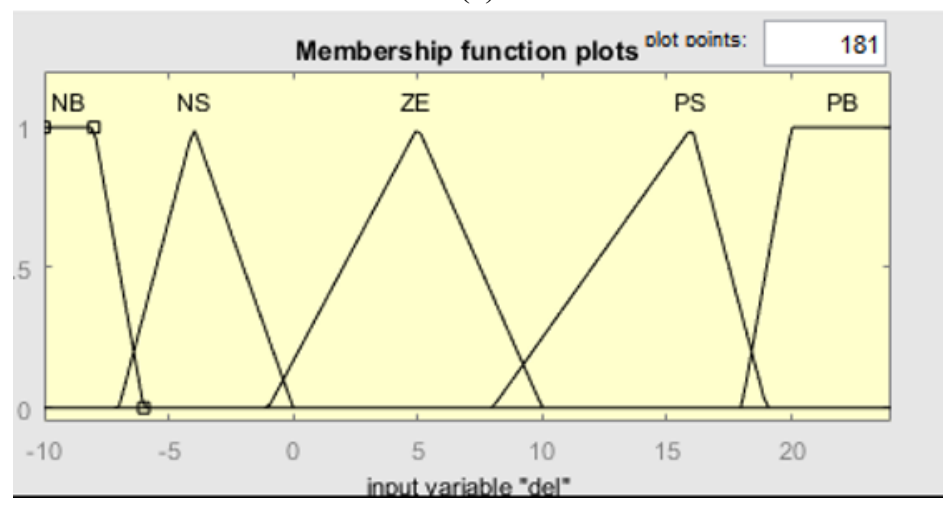

(b)

Fig. 3. MF fuzzy logic input (a) error (e) and (b) delta error $(\Delta \mathrm{e})$

The fuzzy type used is Takagi Sugeno because it is considered to be suitable for the plant, and the resulting output is a numerical number, not a fuzzy set. The type-2 fuzzy logic control system design uses three variations of FOU (Footprint of Uncertainty) namely FOU $\pm 0.1, \pm 0.3$, and \pm 0.5 with the input in the form of error (e) and delta error $(\Delta \mathrm{e})$ and output namely duty cycle (D). Fuzzy logic output type-2 in the form of the duty cycle of the three FOU variations is compared to find the most appropriate FOU width to be applied to the system used. The results of the comparison show that the best duty cycle output among 
the three variations of FOU is FOU \pm 0.3 . The MF input and output used in fuzzy logic type-2 have the same number, value, and naming as MF used in fuzzy logic.

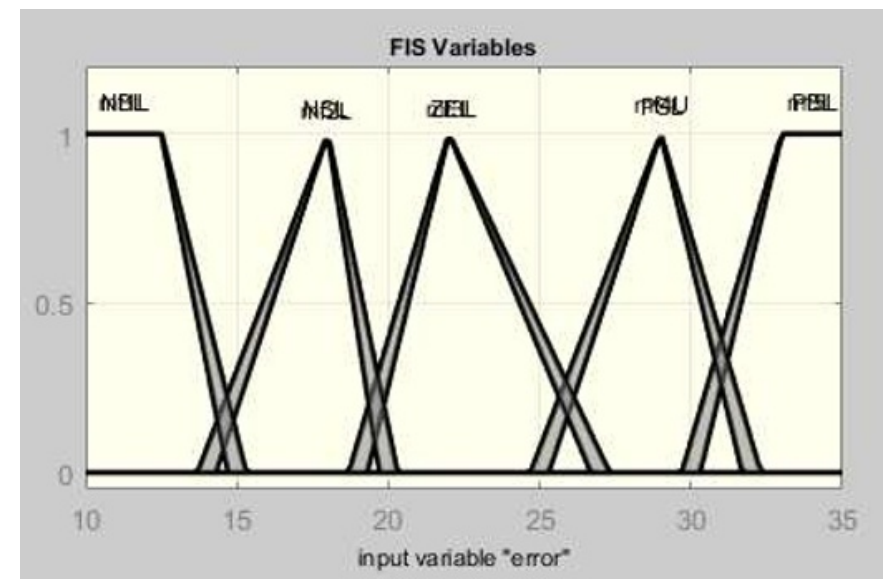

(a)

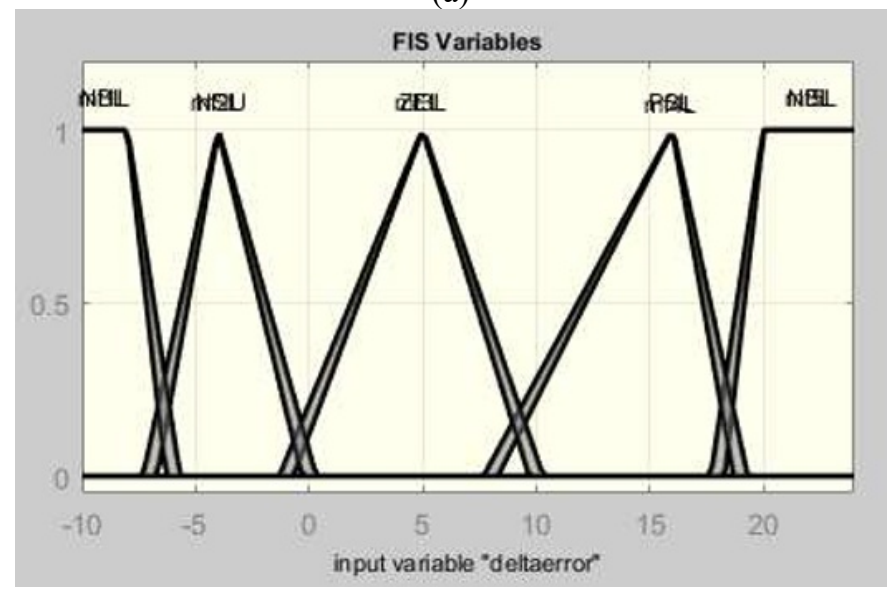

(b)

Fig. 4. MF Fuzzy Logic Type-2 Input (a) error (e) and (b) delta error $(\Delta \mathrm{e})$

The MF used in type 2 fuzzy logic is NB (Negative Big), NS (Negative Small), ZE (Zero), PS (Positive Small), and PB (Positive Big). Every MF in fuzzy logic type-2 has upper and lower limits, which limit the FOU region. Input in the form of crisp numbers expressed in the fuzzy membership function. It processed in an inference engine that has the principle of causation (IF-THEN) with a rule base that functions to regulate fuzzy output following the input received by the system. The rule base is a collection of causal rules that are used to make final decisions from fuzzy logic. The rule base design is done by a trial and error system to find the rule base design that is considered the most appropriate for the system. With the number of input and output membership functions, each of which is five, the rule base can design with 25 . The results of the rule base design applied to the system are as shown in Table 4. 
Table 4. Rules Base of Fuzzy Logic

\begin{tabular}{|c|c|c|c|c|c|c|}
\hline \multicolumn{2}{|c|}{} & \multicolumn{5}{|c|}{ e } \\
\cline { 3 - 7 } \multicolumn{2}{|c|}{} & NB & NS & ZE & PS & PB \\
\hline \multirow{4}{*}{$\Delta \mathbf{e}$} & NB & NS & PS & ZE & PS & PS \\
\cline { 2 - 7 } & NS & PS & PS & PB & PB & PS \\
\cline { 2 - 7 } & ZE & PS & PB & PB & PB & PB \\
\cline { 2 - 7 } & PS & PS & PS & PB & PB & PB \\
\cline { 2 - 7 } & PB & PB & PS & ZE & PS & PB \\
\hline
\end{tabular}

Table 4 shows the 25 rule bases used in the design of type- 2 fuzzy and fuzzy logic control system. The design of the rule base is made by considering the input error (e) and delta error $(\Delta \mathrm{e})$ as well as the decision of the value of the duty cycle output generated from fuzzy logic or type-2 fuzzy to fit the buck-boost converter input duty cycle parameters to produce the output voltage according to the desired results. The operator used in designing the rule base is the AND operator. The output in the form of a duty cycle has the following parameters in Table 5.

Table 5. Output parameter (D)

\begin{tabular}{cccccc}
\hline MF & NB & NS & ZE & PS & PB \\
\hline Parameter & 0.34 & 0.4 & 0.46 & 0.5 & 0.52
\end{tabular}

The output of the designed fuzzy logic is the duty cycle value (D). The output design in the FIS editor has a range of values from 0 to 1 . Membership function (MF) used is the same as MF in the input error (e) and delta error $(\Delta \mathrm{e})$, namely NB, NS, ZE, PS, and PB.

\section{Results and Discussions}

\subsection{Simulation test of MPPT tracking based on fuzzy logic type-2}

Tracking simulation is carried out to know the comparison of MPPT controller output power based on fuzzy logic type 2 that previously design with variations in climatic conditions. The comparison makes between the output of a fixed PV system and the active dual-axis solar tracker system. Primary data that uses as input include PV module surface temperature data, solar irradiation data, and wind speed data. Primary data is taken every 30 min intervals on the 25th of April, 2018, from 06:00 to 17:00 with data collection routes starting from the Institut Teknologi Sepuluh Nopember towards Jembatan Merah Plaza and back again to Institut Teknologi Sepuluh Nopember. Temperature data and solar irradiation from each system plotted for comparison. 


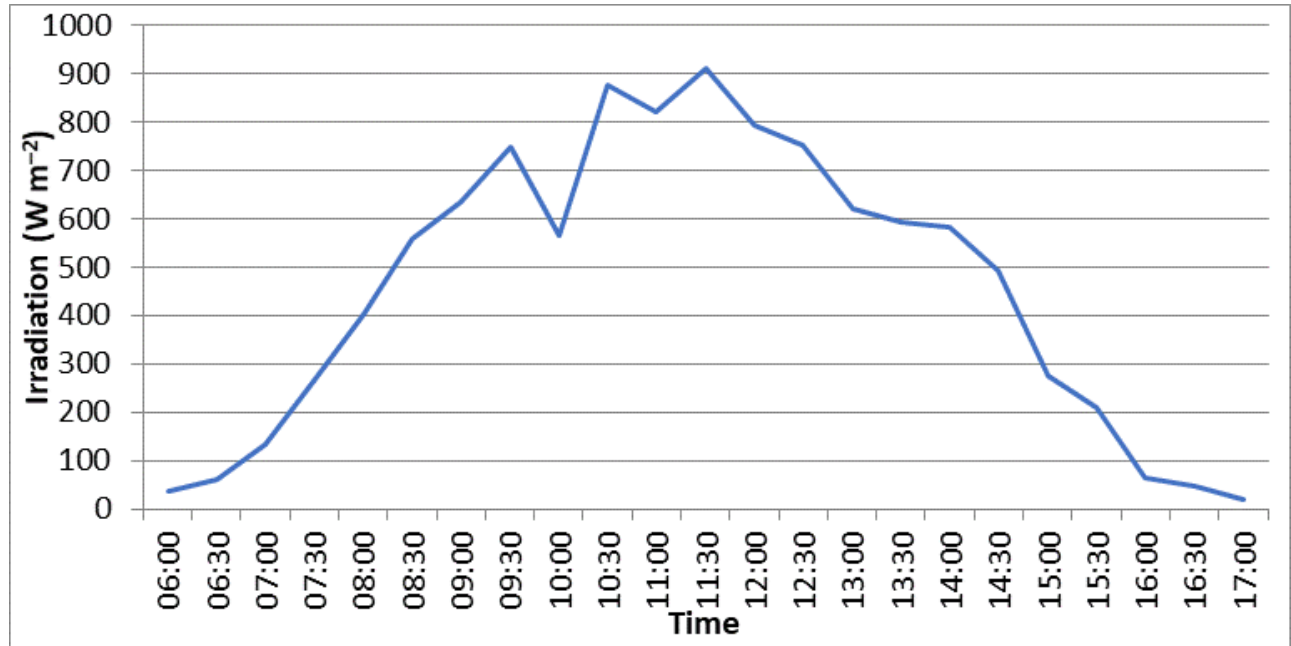

(a)

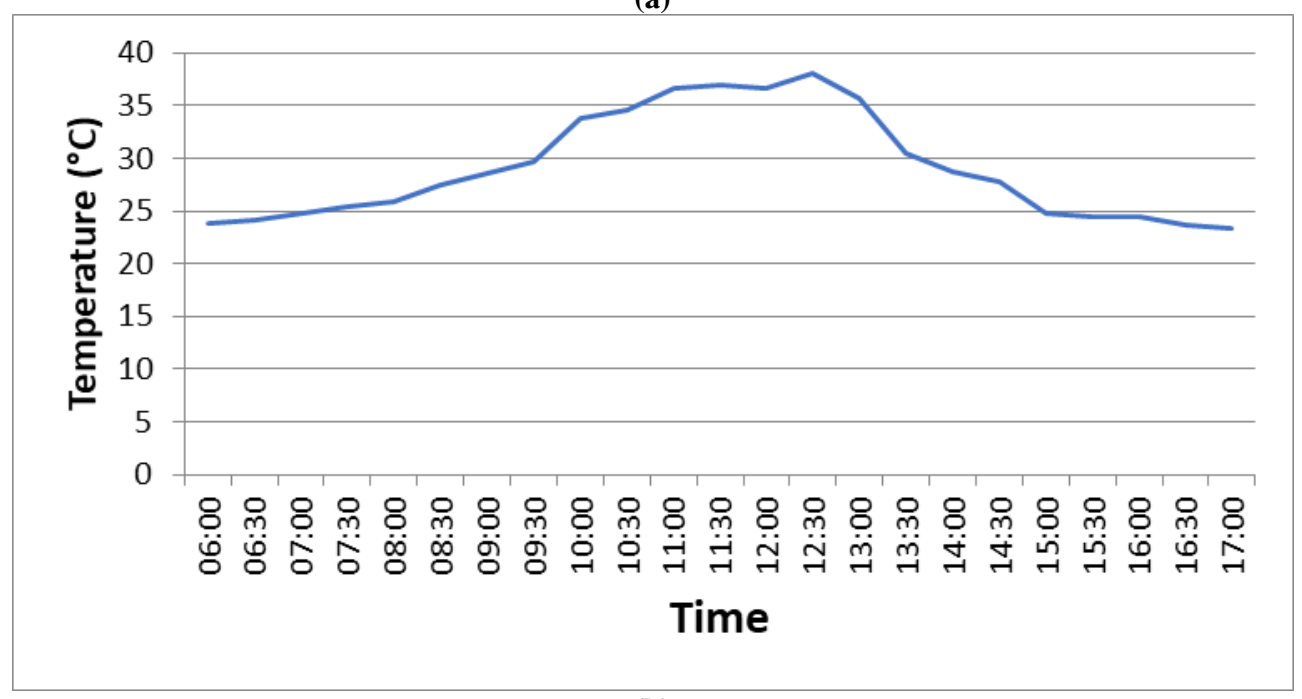

(b)

Fig. 5. (a) Irradiation and (b) Temperature of PV Fixed for 11 Hours of Operation

Irradiation value began to increase every hour from 06.00 WIB with irradiation value is still low at $32.7 \mathrm{~W} \mathrm{~m}^{-2}$. The peak value of the highest solar irradiation is at 11:30, with a value of $912.5 \mathrm{~W} \mathrm{~m}^{-2}$. The decline in the value of solar irradiation began after 11:30 until 17:00 when it was almost sunset with irradiation value reached only $18.4 \mathrm{~W} \mathrm{~m}^{-2}$. At 06:00 after the sun began to rise, the temperature value is $28.2^{\circ} \mathrm{C}$ and has increased to reach the peak of the highest temperature at 12.00 that is when the sun is directly above the PV module perpendicular to the value of $60.2{ }^{\circ} \mathrm{C}$. The temperature value starts to decrease after the highest peak is reached after 12:00 until 17:00 with the PV module surface temperature only reaches $30.6^{\circ} \mathrm{C}$. Solar irradiation data and the system is active dual-axis solar tracker contained in Figure 6. 


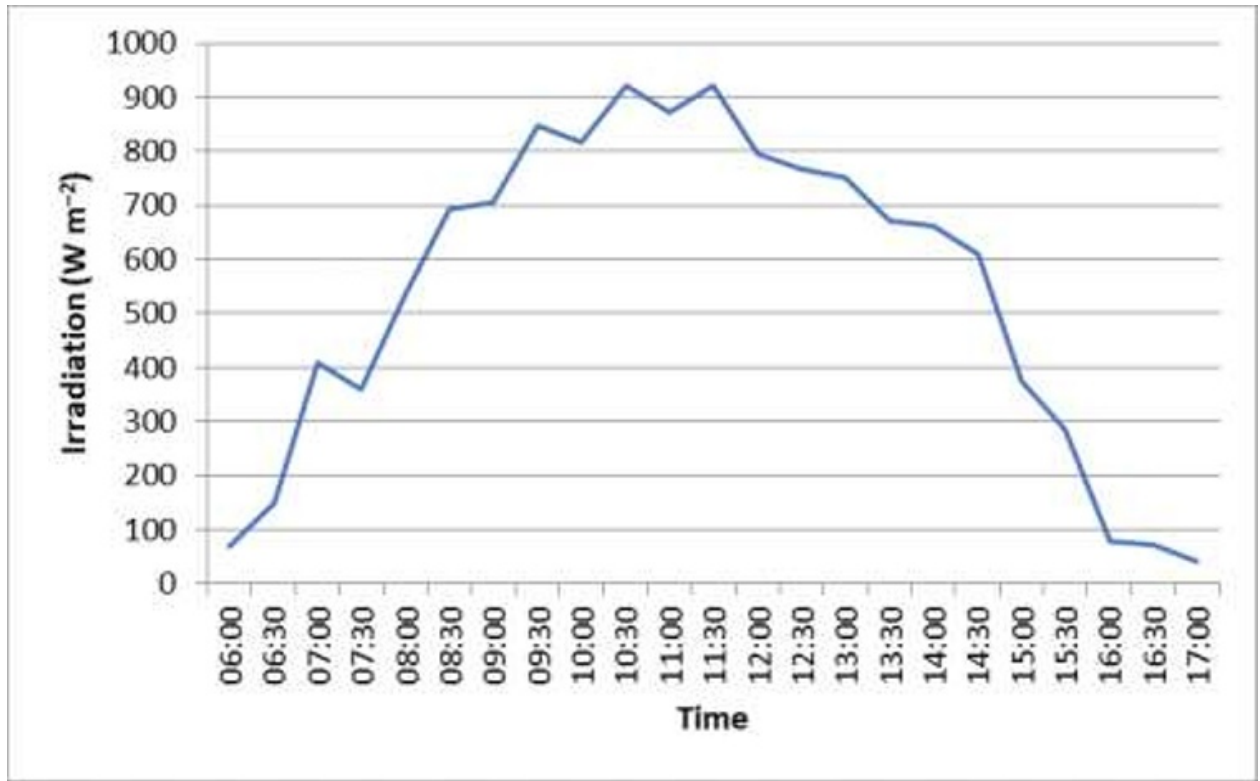

(a)

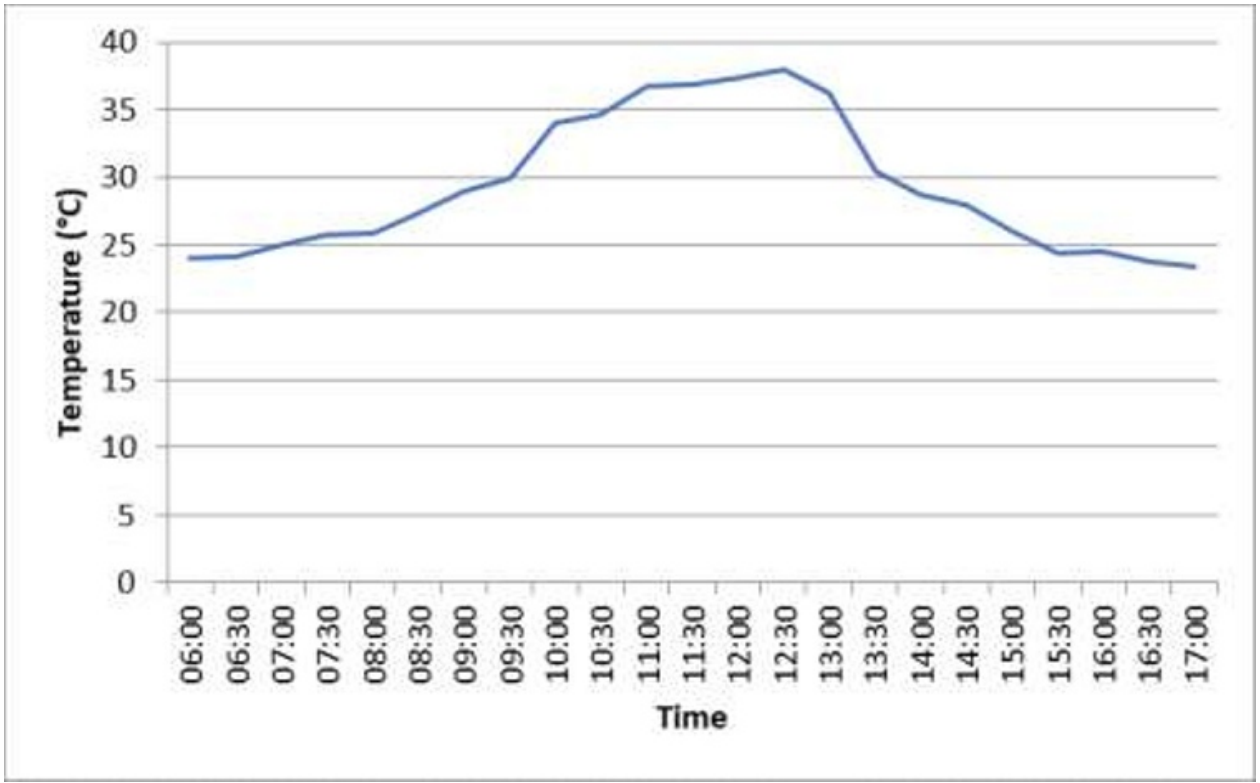

(b)

Fig. 6. (a) Irradiation and (b) temperature of active dual-axis solar tracker for 11 hours of operation

Increasing the value of irradiation began at 06:00 with the sun irradiation value is still low at $70.1 \mathrm{~W} \mathrm{~m}^{-2}$. Solar irradiation value increases with an increase of time with the highest peak value at 11:30 WIB 923.2 $\mathrm{W} \mathrm{m}^{-2}$. The decline in the value of solar irradiation began after 11:30 until 17:00 when the sun starts to sink irradiation values reach $47 \mathrm{~W} \mathrm{~m}^{-2}$. The value of PV surface temperature measured at 06:00 after the sun began to rise was $28.4{ }^{\circ} \mathrm{C}$, then increased until it reached the peak of the highest temperature at 10:30 with a 
value of $63.6^{\circ} \mathrm{C}$. A significant decrease in temperature began after 11:30 until 17:30 with the PV module surface temperature reaching $32.2{ }^{\circ} \mathrm{C}$.

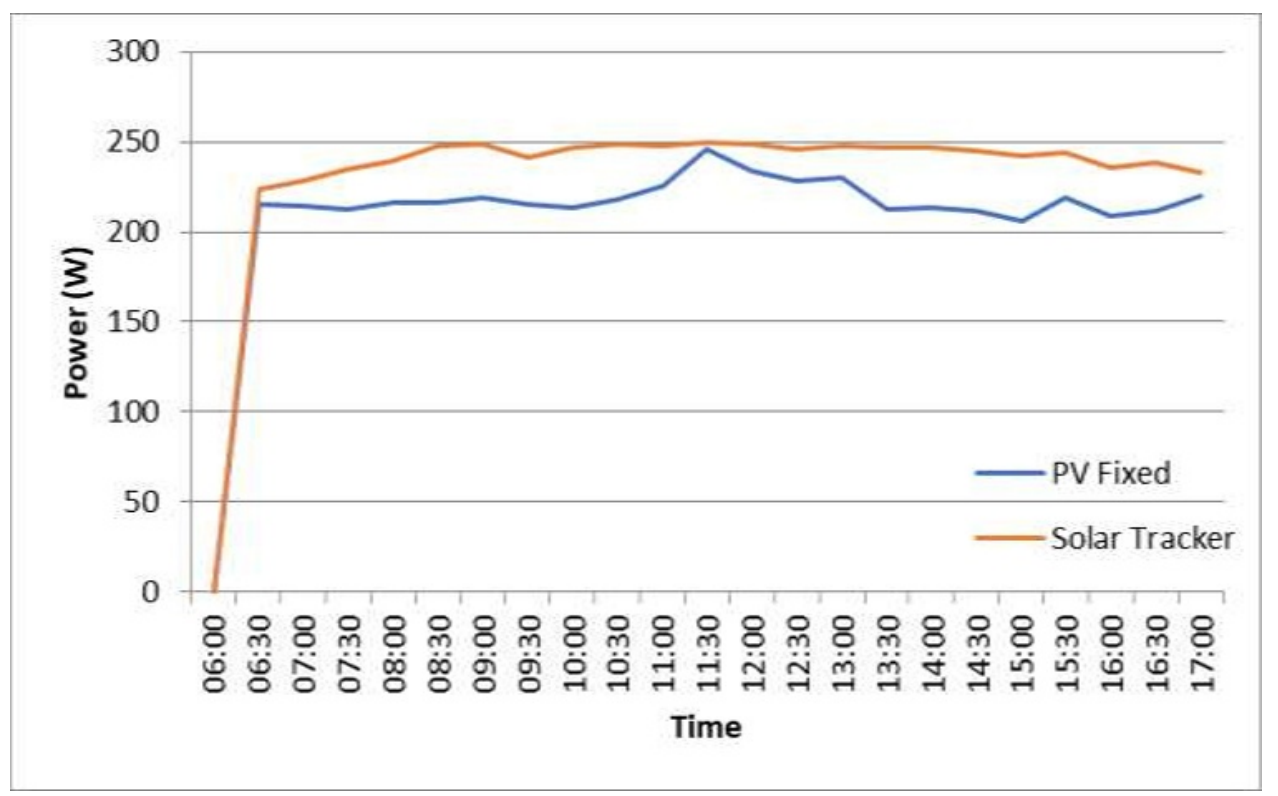

Fig. 7. Comparison power output of PV fixed and active dual-axis solar tracker with type-2 fuzzy logic control

Figure 7 shows the comparison of the output power of MPPT based on type-2 fuzzy logic between fixed PV and active dual-axis solar trackers. The power compared is the output of the buck-boost converter. The converter buck-boost input is the voltage output from the PV fixed or active dual-axis solar tracker. The duty cycle is the output of the fuzzy logic control type-2. The comparison results show that the output power of the active dualaxis solar tracker is better than the fixed PV output power with an average output power respectively of $231.9 \mathrm{~W}$ and 209.4 W. Most of the output power points of the active dualaxis solar tracker have values close to the set point of $250 \mathrm{~W}$ and are quite stable with slight power fluctuations. Power output started to rise and approach the set point of $250 \mathrm{~W}$ with a value of 247.9 at $08: 30$. The peak power achieved at 11:30 when the module PV is perpendicular to the sun's position with a value of $249.8 \mathrm{~W}$ then began to decline until 17:30 with a power of $232.6 \mathrm{~W}$. The simulation results on the fixed PV look less stable. There are more power fluctuations when compared to the output of the active dual-axis solar tracker. Power starts experiencing a significant increase of 11.00. The output value is $225.35 \mathrm{~W}$, and then the highest peak power achieves that is $245.75 \mathrm{~W}$ at $11: 30$ when the sun's position is perpendicular to the direction of fixed PV.

\subsection{Simulation test of MPPT tracking based on fuzzy logic}

The simulation test of MPPT tracking based on fuzzy logic is done to find out the output power and its comparison with MPPT based on type 2 fuzzy logic. This simulation is comparing two different systems, namely PV fixed and active dual-axis solar tracker. 


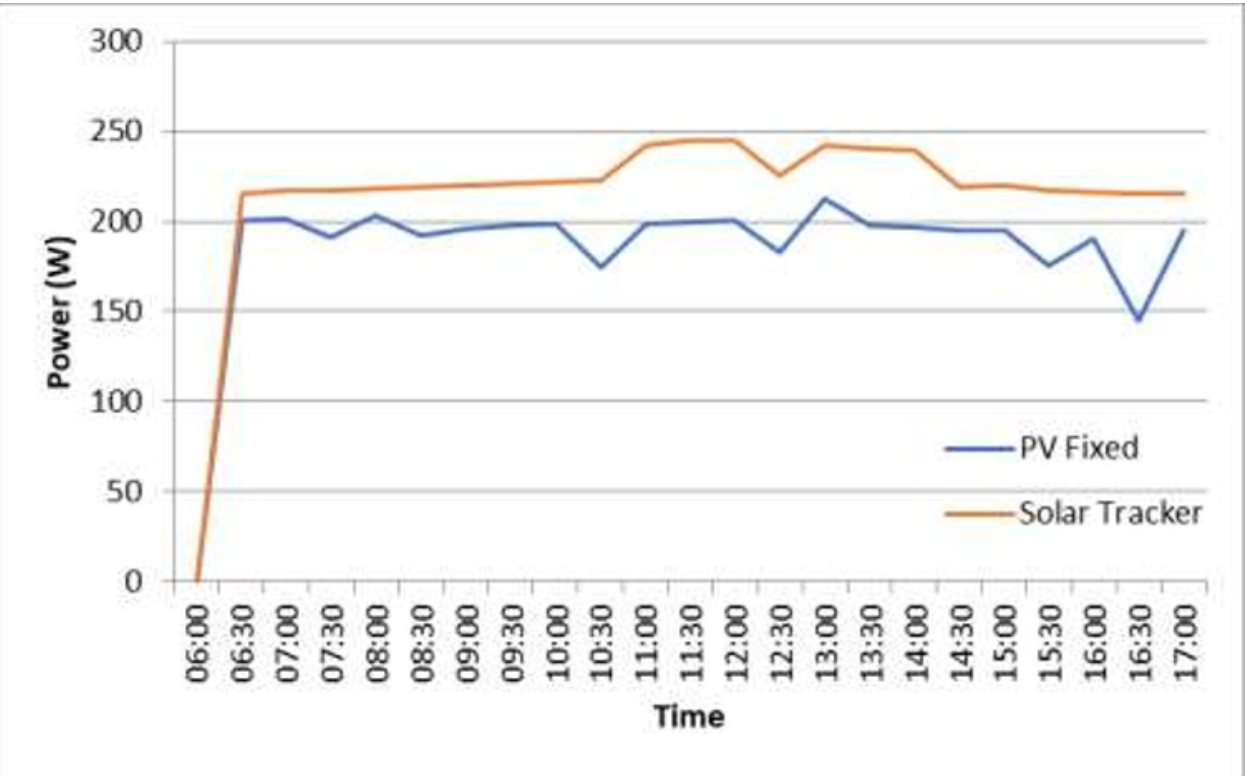

Fig. 8. Comparison of the power output of PV fixed and active dual-axis solar tracker with fuzzy logic control

The average value of the output power, respectively, from the fixed and active PV dualaxis solar tracker, is worth $188729 \mathrm{~W}$ and $219.96 \mathrm{~W}$. However, the average value of output power approaching the $250 \mathrm{~W}$ set point is still low. On active dual-axis solar tracker, the highest peak power is $245187 \mathrm{~W}$ at 13:00. The value of the output power decreases can be caused by one of them because the membership function (MF) in fuzzy logic is not following the characteristics of the input data that comes into the fuzzy logic control. Another factor that can cause a decrease in the value of the output power is because the plant only matches an adaptive type controller.

\subsection{P\&O based MPPT tracking test simulation-2}

The Perturb and Observe (P\&O) method is a conventional control method in MPPT. The tracking test simulation using the $\mathrm{P} \& \mathrm{O}$ method is performed to know the output power and comparison between MPPT systems that apply conventional control methods such as the Perturb and Observe (P\&O) method and MPPT that applies control methods with artificial intelligent concepts such as fuzzy logic and type-2 fuzzy logic. Simulation test tracking MPPT based P\&O is to compare the power outputs of the two systems that are similar to the simulation test of tracking previously that system of the PV fixed and active dual-axis solar tracker. Input from the controller P\&O is the voltage, and current are out of PV fixed or of the active dual-axis solar tracker with output in the form of a duty cycle, which then becomes the input converter buck-boost after generated into a signal PWM by PWM generator. 


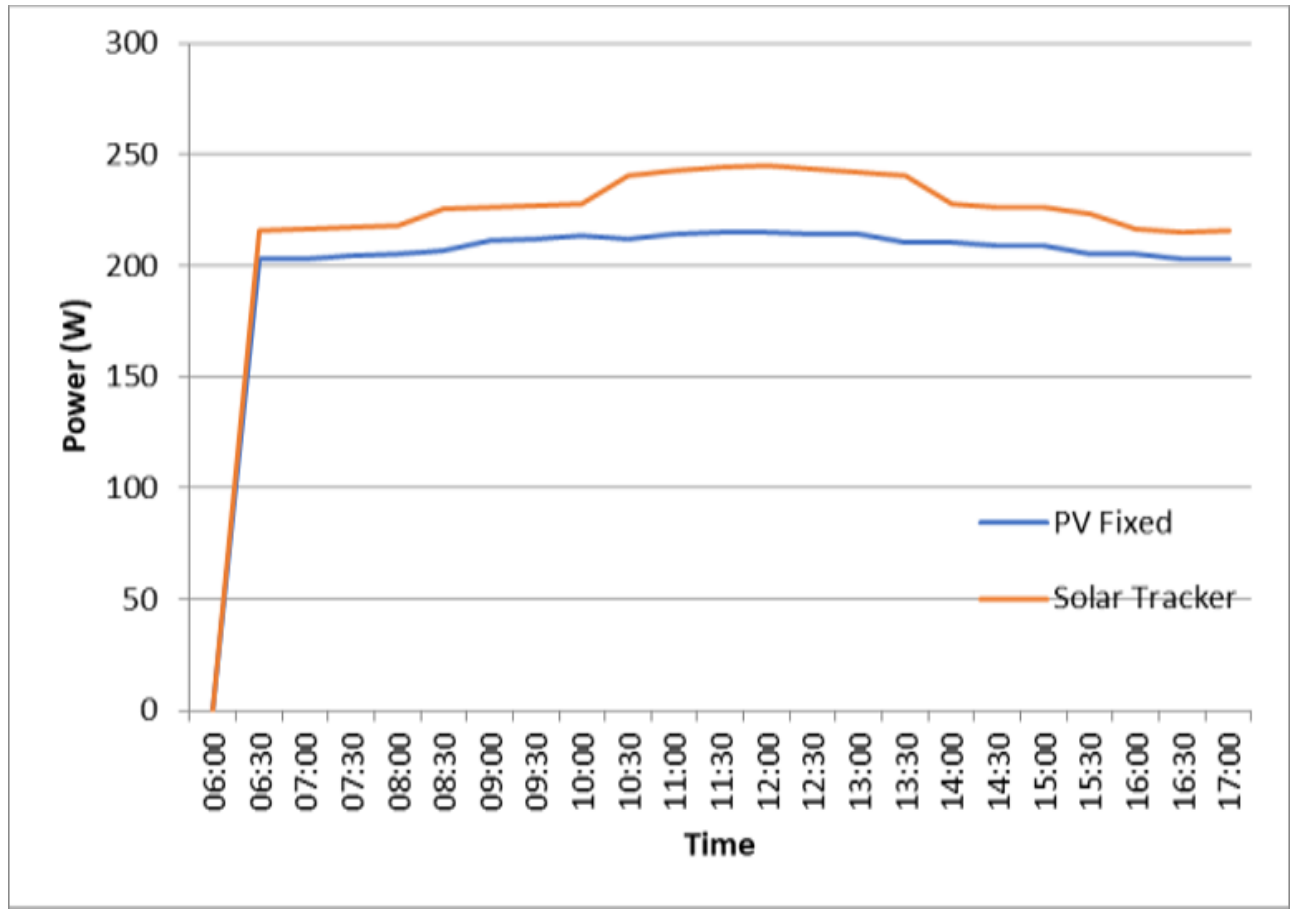

Fig. 9. The comparison power output of $\mathrm{Pv}$ fixed and active dual-axis solar tracker with $\mathrm{P} \& \mathrm{O}$ control

The results of the comparison show that the active power output of the dual-axis solar tracker is better than the fixed PV with average output power, respectively $222.867 \mathrm{~W}$ and 204.325 W. The curve of a fixed PV shows stable data without extreme power fluctuations. The peak power in a fixed PV reaches at 12:00 with a value of 215 W. System Active dualaxis solar tracker showed a reasonably stable with little fluctuation in power. Output power starts to increase at 08:30 and 10:30 with values respectively $225.3 \mathrm{~W}$ and $240.6 \mathrm{~W}$. The highest power value is achieved with a value of $245.186 \mathrm{~W}$ at 12.00 and then has decreased until 17:30 with a power of $214.38 \mathrm{~W}$.

\subsection{Comparison of the increased output power of the controller}

The comparison of the output power of each controller that simulated on the PV fixed and active dual-axis solar tracker then compare. A comparison of the increase in power output begins to calculate the power of any results of the simulation obtained. Equation (10) is used to find the percentage increase in the output power of each controller that has been simulated and tested. The comparison of the simulation of PV fixed and active dual-axis solar tracker for each controller and on the results of the controller simulation for each system PV fixed and active dual-axis solar tracker.

$$
\text { Increased Power Output }=\left(\frac{P_{\text {tracker }}-P_{P V \text { fixed }}}{P_{P V} \text { fixed }}\right) 100 \%
$$




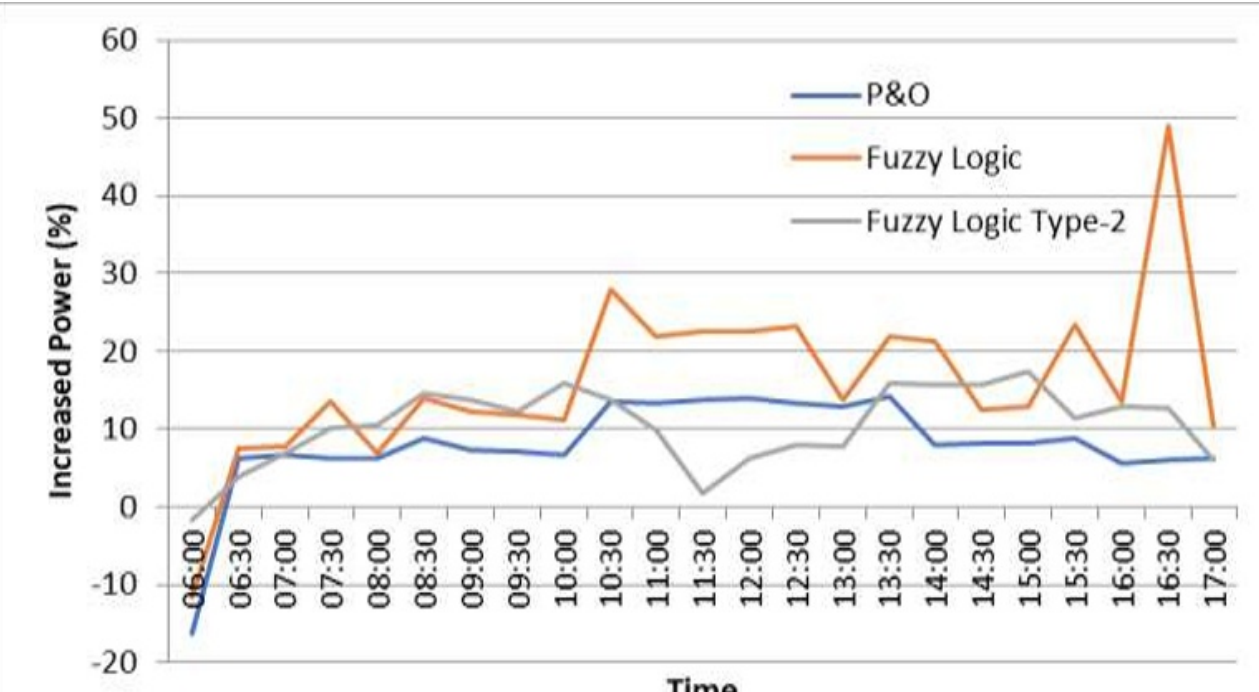

Time

Fig. 10. Comparison of increased output power of each controller

Figure 10 shows the comparison of power increases between three controllers that have been simulated and tested on a fixed and active dual-axis solar tracker PV system. The average increase in the output power of each controller from P\&O, fuzzy logic, and type-2 fuzzy logic are respectively $8 \%, 16.1 \%$, and $10.48 \%$. The peak value of the highest increase in output power is $48.98 \%$ obtained from the MPPT system based on fuzzy logic precisely at 16:30 from the output power of a fixed PV system valued at $144.5 \mathrm{~W}$ to the output power of the active dual-axis solar tracker system with an output power value of 215.3 W. The highest increase in output power obtained on the P\&O-based MPPT system was at 13.30 with an increase of $14.12 \%$ from the value of the fixed PV system output power of $210.7 \mathrm{~W}$ to $240.5 \mathrm{~W}$ the results obtained by the active dual-axis solar system tracker.

The comparison of the increase in output power is not only done on the MPPT system but also systems without MPPT. This comparison made between the output power coming out of the fixed PV system and the active dual-axis solar tracker without connecting to the buck-boost DC-DC controller and converter. The results obtained from the average comparison of the increasing power output between the two systems without connecting with MPPT is $43.69 \%$ with the highest increase at 06:30 amounting to $165.78 \%$ with the difference in output power by $27.07 \mathrm{~W}$ from the output power of the PV system fixed value of $16.3 \mathrm{~W}$ to $43.39 \mathrm{~W}$, the output of the active dual-axis solar tracker system.

\section{Conclusions}

The parameters that influence the design of active dual axis solar tracker and MPPT based on type-2 fuzzy logic are the PV module surface temperature, solar irradiation received by the PV, wind speed, load resistance, and controller, while the parameters that influence the fuzzy logic type-2 which includes parameters in the form of input error (e), delta error input $(\Delta \mathrm{e})$, output duty cycle $(\mathrm{D})$, membership function, limits of each membership function, rule base, defuzzification parameters and footprint of uncertainty (FOU). The increase in average output power that successfully obtained by applying MPPT based on type- 2 fuzzy logic on the active dual-axis solar tracker system was $10.48 \%$. The highest increase is 
$17.48 \%$ from the fixed PV system obtained at 15:00. The difference in power from a fixed $\mathrm{PV}$ system with an active dual-axis solar tracker is $36.08 \mathrm{~W}$, from an output power value of $206.332 \mathrm{~W}$ to $242.4 \mathrm{~W}$.

\section{References}

1. B. Dudley, BP Statistical Review of World Energy June 2017. British Petroleum. (2017). [Online Report]. pp. 52. https://www.ourenergypolicy.org/resources/bpstatistical-review-of-world-energy-june-2017/

2. N. Altin, Single phase grid interactive PV system with MPPT capability based on type-2 fuzzy logic systems, 2012 International Conference on Renewable Energy Research and Applications (ICRERA), (Nagasaki, Japan, 2012), pp. 1-6. https://ieeexplore.ieee.org/document/6477335

3. M.S. Munna, M.A.I. Bhuyan, K.M. Rahman, M.A. Hoque, Design, implementation and performance analysis of a dual-axis autonomous solar tracker, 2015 3rd International Conference on Green Energy and Technology (ICGET), (Dhaka, Bangladesh, 2015), pp. 1-5. https://ieeexplore.ieee.org/abstract/document/7315104

4. S. Soltani, M.J. Kouhanjani, Fuzzy logic type-2 controller design for MPPT in photovoltaic system, 2017 Conference on Electrical Power Distribution Networks Conference (EPDC), (Semnan, Iran, 2017), pp. 149-155.

https://ieeexplore.ieee.org/document/8012756

5. T. Kaur, S. Mahajan, S. Verma, Priyanka, J. Gambhir, Arduino based low cost active dual axis solar tracker, 2016 IEEE 1st International Conference on Power Electronics, Intelligent Control and Energy Systems (ICPEICES), (Delhi, India 2016), pp. 1-5. https://ieeexplore.ieee.org/document/7853398

6. H-C. Lu, T-L. Shih, Fuzzy system control design with application to solar panel active dual-axis Sun tracker system, 2010 IEEE International Conference on Systems, Man and Cybernetics, (Istanbul, Turkey, 2010), pp. 1878-1883.

https://ieeexplore.ieee.org/document/5642275/

7. M.H.M. Sidek, N. Azis, W.Z.W. Hasan, M.Z.A.A. Kadir, S. Shafie, M.A.M. Radzi, Energy, 124,124:160-170(2017).

https://linkinghub.elsevier.com/retrieve/pii/S0360544217301755

8. I. Abadi, A. Soeprijanto, A. Musyafa, A. Design of single axis solar tracking system at photovoltaic panel using fuzzy logic controller. 5th Brunei International Conference on Engineering and Technology (BICET 2014). (Bandar Seri Begawan, Brunei). IET Conference Proceedings, 2014, https://digital-library.theiet.org/content/conferences/10.1049/cp.2014.1086

9. I. Abadi, A. Musyafa, A. Soeprijanto, Int. Rev. Model. Simulations, 8,6: 640-652(2015). www.doi.org/10.15866/iremos.v8i6.7907

10. I. Abadi, D. Nur Fitriyanah, A. Ul Umam, AIP Conference Proceedings, 2088:20041(2019). https://aip.scitation.org/doi/abs/10.1063/1.5095293

11. G. Yu, Y. Lin, Design of MPPT by using interval type-2 T-S fuzzy controller, 2014 IEEE International Conference on Fuzzy Systems (FUZZ-IEEE), (Beijing, China 2014), pp. 734-738. https://ieeexplore.ieee.org/document/6891792

12. E.B. Babatunde, Solar Radiation, a Friendly Renewable Energy Source, Solar Radiation, IntechOpen, [Online] Available from: https://www.intechopen.com/books/solar-radiation/solar-radiation-a-friendlyrenewable-energy-source (2012). [Accessed on 27th of August, 2019]. 
13. I. Abadi, A. Musyafa', A. Soeprijanto, Int. Rev. Electr. Eng., 10,3:390-398(2015). www.doi.org/10.15866/iree.v10i3.6090 